\title{
ANNOUNCEMENT \\ European Geophysical Society XII General Assembly
}

Strasbourg, France, 9-14 April 1987

Among the symposia and open sessions included in the scientific program are the following: Seismic Hazards; Paleomagnetism and Geophysical and Geological Events; Hydrology and Glaciology; Land Surface Processes for Climate Research Including Satellite Measurements; Clouds and Climate; Oceanic Studies of the Mediterranean; Computer Simulations in Fluid Dynamics-Earth, Atmospheres, and Space Plasmas; Society Lecture: Change in Climate Variations and Water Resources.

Call for papers: You are invited to submit abstracts of work done in any area of geophysics within the framework of the EGS. Abstracts should be typed in the EGS/AGU format. Submit your abstract to one of the conveners and send a copy to the chairman of the program committee. A list of conveners was included in the second circular, which was distributed to EGS members in October 1986. Non-EGS members should contact one of the chairmen listed below. Deadline for receipt of abstracts is 9 January 1987. Abstracts will be published in the EUG periodical Terra Cognita.

For further details concerning the scientific program, please contact the Chairman of the Program Committee:
Dr. Arne K. Richter
MPI für Aeronomie
Postfach 20
D-3411 Katlenburg-Lindau,
Federal Republic of Germany

For meeting and registration information, please contact the Chairman of the Local Organizing Committee:

\author{
M. M. Cara \\ Institut de Physique du Globe \\ 5 rue $R$. Descartes \\ F-67084 Strasbourg, Cedex, France
}

For information on travel grants for young scientists, please contact the EGS General Secretary:

\author{
Dr. G. M. Brown \\ Department of Physics \\ University College of Wales \\ Aberystwyth SY23 3BZ, United Kingdom
}

